food, and all the Indians of the region collect eggs during the nesting season. In 196725,000 eggs were taken from one area and sold in markets in some major Bolivian towns.

If the climatic change continues to force the rare James's flamingo into new areas, away from the seclusion of the Laguna Colorada and the surrounding semi-explored wilderness, their numbers could be reduced drastically. As the precise status of the species is not known, it is difficult to estimate how tolerant it will be of any change.

\title{
Bears and Birds of Prey in Italy
}

An interim report on the Abruzzo brown bear survey in Italy (to which the FPS/WWF Revolving Fund contributed) estimates a density of one bear for each five square kilometres in an area (Monti della Difesa, near Pescasseroli) that is believed to provide the optimum bear habitat. In the 360 square $\mathrm{kms}$ under observation there were at least 70 bears, from which it was calculated that, as the bears' range covers at least 520 square $\mathrm{kms}$, the total population may be not less than 100 animals. The report recommends that both refuge and feeding areas be made strict reserves, with an absolute prohibition against cutting plants favoured by bears (66 per cent of their food was found to be herbaceous or fruit); a planting programme of suitable food plants; indemnity payments for damage to domestic stock (which was done in 1965 and 1970 by the Italian WWF, and is now being done by the National Park authorities for the first time in its history), and the reintroduction of herbivores.

The Italian WWF reports that the white-tailed eagle is now extinct in Italy: the last breeding pair has not been seen for three years at its nesting site in Sardinia. The lammergeier is also now believed to be extinct in Italy, and the golden eagle in a very precarious position. Poison baits (often set by hunters) are one of the chief causes of wildlife destruction in Italy, especially to birds of prey, wolves, wild cats and brown bears.

\section{Conservation Filmstrip}

Now that conservation is a word in everyday use, we have the second and more difficult task of explaining what it really means, and a filmstrip such as Dr. D.H. Dalby's Nature Conservation in the British Isles makes a valuable contribution. His photographs are unemotional statements of fact and the lecture notes full and informative, with background information in italics. The filmstrip is divided into three sections with inevitably some overlap between them. The first 'Some major threats' has twelve frames - it seems a pity there was not room for more about such farming techniques as removal of hedges and the effects of coastal development; the second 'How natural are our habitats?' discusses the evolution of our countryside and provokes the question, What is it we are trying to conserve? The third is concerned with conservation measures. Aimed principally at secondary schools, naturalists' trusts and amenity bodies, there is, surprisingly, no mention of Colleges of Education or Teachers' Centres. The education of future generations of adults is fundamental in conservation, but first we must educate our teachers.

The filmstrip, one of a series on the Environment published by Diana Wyllie, is available in the full frame picture size $(35 \mathrm{~mm} \times 24 \mathrm{~mm})$ at $£ 3$ and half frame $(24 \mathrm{~mm} \times 18 \mathrm{~mm})$ at $£ 2.50$, the larger one being easy to cut up and mount as individual slides. 